\title{
HABITUS E VIRTUDE EM PEDRO ABELARDO: UMA DUPLA HERANÇA
}

\author{
Guy Hamelin* \\ hamelingr@hotmail.com
}

RESUMO Pedro Abelardo apresenta na sua obra uma teoria da virtude de natureza, à primeira vista, aristotélica. Ao que parece, essa concepção também contém diferentes elementos estoicos, que não se opõem necessariamente à visão do Estagirita. Todavia, o essencial da interpretação da Escola do Pórtico acerca da virtude difere da explicação dada por Aristóteles. No presente estudo, pretendemos examinar, primeiro, a indole da virtude como habitus na obra de lógica de Abelardo. Nesse caso, não há dúvida de que predomina a influência aristotélica. Em seguida, indicamos outras particularidades da virtude encontradas, desta vez, em tratados éticos e teológicos do nosso protagonista, as quais se revelam antes de caráter estoico. Em suma, projetamos identificar as diferentes fontes antigas e os principais intermediários latinos usados por Abelardo para elaborar a sua própria teoria da virtude. Trata-se de deixar clara a influência filosófica dominante em Abelardo sobre essa questão da virtude, já que este lógico não pode harmonizar teses substancialmente inconciliáveis.

Palavras-chave Abelardo, Aristóteles, estoicismo, ética, virtude, habitus.

ABSTRACT Peter Abelard in his work presents a theory of virtue, which is, at first sight, of Aristotelian nature. It seems that this view also contains different Stoic elements, but they are not necessarily opposed to Stagirite's

* Professor do Departamento de Filosofia, Universidade de Brasília (UnB). Artigo recebido em 27/05/2014 e aprovado em 03/08/2014.

KRITERION, Belo Horizonte, nº 131, Jun./2015, p. 75-94 
vision. However, the essentials of the Stoa School about virtue differ from the explanation given by Aristotle. In this paper, we intend to examine, first, the nature of virtue as habitus in Abelard's work on logic. In this case, there is no doubt that Aristotle's influence on this topic predominates. Next, we specify other features related to virtue found, this time, in ethical and theological treatises of our protagonist that appear to be basically Stoic. In short, we want to identify the different ancient sources and the main Latin mediators used by Abelard to elaborate his own theory of virtue. In other words, we would like to shed light on the predominant philosophical authority on Abelard's theory of virtue since this logician cannot harmonize theses that are fundamentally irreconcilable.

Keywords Abelard, Aristotle, Stoicism, Ethics, virtue, habitus.

\section{Introdução}

A ética de Pedro Abelardo sofre influências variadas, tanto da Escritura e dos Padres da Igreja, quanto dos pensadores pagãos. Entretanto, não há dúvida de que a sua teoria da virtude é inspirada pelos seus predecessores filósofos. Mesmo assim, pode ter alguma hesitação, segundo o texto estudado, no que se refere à fonte exata, da qual Abelardo extrai a sua própria concepção da virtude. Enquanto parece clara que a descrição feita na "Ethica sive Scito teipsum" ("Ética ou Conhece-te a ti mesmo") 1 ou no "Sic et non" ${ }^{2}$ seja de caráter aristotélico, a encontrada no "Dialogus" já não é tão manifesta. Nesse último caso, as influências são diversas, notadamente estoica. Por outro lado, quando examinamos os tratados de lógica do autor em estudo, a análise com relação à natureza ontológica da virtude aproxima-se da de Aristóteles. Em outras palavras, Abelardo mostra-se, no conjunto, favorável à teoria da virtude proposta pelo Estagirita, ainda que o contexto, no qual a sua própria concepção aparece, e muitas das suas especificidades sejam claramente de natureza estoica.

No presente estudo, pretendemos esclarecer essa questão, mostrando a influência precisa exercida por cada um desses principais protagonistas na concepção abelardiana da virtude. Em outros termos, trata-se de deixar claro 
o que é a ascendência de Aristóteles e dos diferentes filósofos estoicos sobre a descrição feita por Abelardo, em vários dos seus tratados, dessa qualidade meritória. Em primeiro lugar, examinamos o essencial da definição da virtude como habitus, tal como é apresentada por nosso autor na sua obra de lógica. Neste caso, é preciso remontar ao Estagirita das "Categorias" para descobrir a origem dessa noção polissêmica de habitus ( ${ }^{\prime} \xi$ $\xi$ ), a fim de identificar o significado preciso correspondente à virtude. Em seguida, expomos diferentes descrições da virtude encontradas em textos éticos e teológicos de Abelardo. Revelam-se então diferentes características e elementos não somente aristotélicos, mas também de natureza estoica, sem esquecer o contexto, no qual aparecem essas explicações, que procede frequentemente da Escola do Pórtico. Em suma, além de identificar as principais fontes e intermediários usados por Abelardo para elaborar a sua própria concepção da virtude como habitus, queremos indicar a qual dessas teorias tem, afinal de contas, a sua preferência.

\section{A noção de habitus}

O que Abelardo entende exatamente por habitus? Para responder a essa pergunta, é necessário se referir, sobretudo, aos tratados de lógica do nosso protagonista, nos quais explica em pormenor a polissemia da noção. Neste momento, é sem dúvida útil apresentar os dois principais textos lógicos usados no presente estudo, já que são pouco conhecidos e de acesso difícil.

Primeiro, a "Logica 'Ingredientibus"”, 4 também conhecida como "Glosas de Milano", consiste em comentários bastante desenvolvidos sobre uma boa parte da logica uetus. O título entre aspas, que corresponde à primeira palavra do tratado, é enganador, dado que parece pouco provável que o conteúdo estava destinado a iniciantes. Trata-se essencialmente de comentários sobre a "Isagoge" de Porfírio, as "Categorias" e o "De interpretatione" de Aristóteles e o "De differentiis topicis" de Boécio. ${ }^{5}$ Nesses textos, Abelardo frequentemente expõe suas próprias ideias sobre questões lógicas debatidas pelos seus contemporâneos. Como é de costume na obra inteira de Abelardo, notadamente nos textos teológicos, a "Logica 'Ingredientibus"” é revisada e

4 "Peter Abaelards philosophische Schriften" (1919-1927). Uma parte da glosa sobre o "De interpretatione", publicada por Geyer nessa edição (pp. 497-503) é espúria e não é de Abelardo. Minio-Paluello (1958) corrige e completa essa edição de Geyer.

5 Esse último comentário foi descoberto e publicado por Dal Pra (Pietro Abelardo, 1954, pp. xxvi-xxxvii e pp. 205-330). Na origem, a “Logica 'Ingredientibus'” também incluía, talvez, um comentário sobre proposições hipotéticas. Cf. Luscombe (1988, p. 281). 
corrigida no decorrer da vida do seu autor, acabando em um texto conhecido sob o nome de "Logica "Nostrorum petitioni sociorum" ou, às vezes, "Glosas de Lunel". Hoje perdido em boa parte, o conteúdo deste último tratado restringese apenas a um comentário elaborado sobre a "Isagoge". ${ }^{6}$ Além dessas glosas e comentários, examinamos outro tratado lógico de Abelardo considerado mais original e conhecido como "Dialectica". ${ }^{7}$ Em parte incompleto, esse texto de maturidade, que também comporta várias revisões, expõe as próprias concepções lógicas do nosso autor.

Examinamos agora o que é dito sobre o habitus na "Logica 'Ingredientibus". Nas suas "Glosas sobre as 'Categorias' de Aristóteles" desse tratado, na parte consagrada aos predicamentos do tempo (quando), do lugar (ubi) e do haver (habere), Abelardo indica que o termo habere pode ser igualmente tomado, à maneira de habitus, como um substantivo (nomen). Distingue então três significados diferentes da palavra habitus. Vejamos o trecho em questão.

"Haver" também se toma como nome, à semelhança de "habitus". E esse habitus possui três significações. De fato, há o habitus que, com a disposição, é colocado sob a primeira espécie de qualidade. Há igualmente o habitus <que se opõe $>$ à privação. Enfim, os habitus são considerados, no mesmo lugar, como propriedades que, segundo o testemunho de Boécio, vêm das coisas exteriores que possuímos. Por exemplo, a partir das armas que possuo, tenho alguma propriedade que se chama "Haver <armas>" ou "estar armado". Na verdade, "estar armado" não designa aqui uma paixão (afecção), ${ }^{8}$ pela qual se afirma "estou armado", "estás armado", mas $<$ designa $>$ certa propriedade, que é dita "Haver" e < que vem $>$ depois de uma afeição inata, permanente e não transitória, como é a paixão. ${ }^{9}$

Entre esses três sentidos de habitus descritos por Abelardo nesse tratado, o primeiro nos interessa acima de tudo no presente trabalho. Reservamos mais adiante a sua análise e explicação. Por enquanto, vamos limitar nosso exame significationes. Est enim habitus qui cum dispositione sub prima specie qualitatis ponitur, est etiam habitus privationis. Praeterea habitus hoc loco dicuntur quaedam proprietates, quae teste Boethio veniunt ex rebus extrinsecis, quae habentur, ut ex armis, quae habeo, quaedam mihi inest proprietas, quae Habere vocatur sive armatum esse. Hoc enim loco armatum esse non passionem designat, a qua sumptum est 'armor, armaris', sed proprietatem quandam quae Habere dicitur post passionem innata et permanens, non transitoria, sicut est passio" ("Glossae super Predicamenta Aristotelis". In: Peter Abaelards Philosophische

Schriften, 1919-1927, p. 258).

"Peter Abaelards philosophische Schriften", 1933.

Petrus Abaelardus. "Dialectica" (1970). Esse tratado é incompleto; faltam essencialmente o início e o fim.

Abelardo refere-se aqui à qualidade afetiva ( dita como terceiro gênero da categoria da qualidade. Cf. Aristóteles. Categorias 8, 9a 27-10a 10. 
aos dois outros significados de habitus, a fim de ressaltar a diferença com o primeiro sentido.

A segunda significação refere-se ao habitus em oposição à privação (priuatio). Esse par constitui uma das quatro duplas de opostos apresentada por Aristóteles nas "Categorias" $10 .{ }^{10}$ Esse último sentido de habitus possui uma extensão ao mesmo tempo maior e distinta, pelo menos em parte, do primeiro.

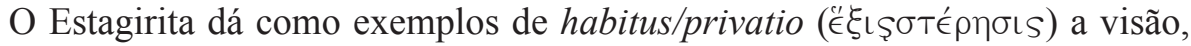
que se opõe à cegueira, e o fato de ser cabeludo, em oposição a ser calvo. ${ }^{11}$ Para explicar melhor a significação do termo habitus em questão, Abelardo afirma que se trata de uma forma de posse (possessio) ou de haver (habere), quando esse último termo é tomado de maneira genérica (generalissimum). ${ }^{12}$

Sem entrar em detalhes, o habitus do primeiro gênero da qualidade distingue-se do habitus, que se opõe à privação, por seu caráter habitualmente adquirido, isto é, inatural ou não inato. Essa característica não parece pertencer ao habitus como posse, que é apresentado, antes, como algo congênito. ${ }^{13}$ Enfatizamos enfim que Agostinho retoma, mutatis mutandis, esse segundo sentido de habitus, oposto à privação, para desenvolver a sua famosa concepção ontológica do mal, como ausência ou privação do bem. ${ }^{14}$ Como diz o Bispo de Hipona, seguindo assim de perto, via Plotino, Aristóteles sobre essa questão, a ausência de algo não é uma coisa. ${ }^{15}$ A cegueira não é alguma coisa, mas, sim, a ausência da visão, assim como a calvície é a privação em parte ou em totalidade de cabelos. O que se opõe a algo não é uma coisa ou o nada (nihil), na medida em que o nada seria algo. ${ }^{16}$ Daí o mal, que se opõe ao bem, não constitui uma entidade ontológica, nem é algo, já que é, antes, uma ausência, ou seja, uma privação do bem, da mesma maneira que a cegueira, como ausência de visão, não é algo, mas a ausência da visão. Deus simplesmente não pode criar uma

10 Aristóteles. "Categorias" 10, 11b 20, 25-35.

$11 \mathrm{lbid}$. Ver igualmente a "Metafísica", livro f, capítulo 22, onde Aristóteles distingue de maneira mais precisa

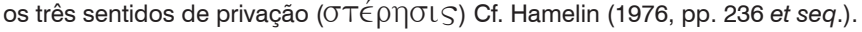

12 Petrus Abaelardus. "Dialectica" (1970, pp. 108-109).

13 Aristóteles. "Categorias" 10, 12a 28-32.

14 Cf. Agostinho. "Confissões" III, 7, 12 e VII, 12, 18 et seq.

15 Cf. Agostinho. "De moribus Manichaeorum" 2, 2; "Contra epistolam Manichaeorum quam vocant fundamenti" 40, 46; "De natura boni contra Manichaeos" 20; "De civitate Dei contra paganos" $19,13$. "Moral evil is thus a privation of right order in the created will. This doctrine of evil as a privation was the doctrine of Plotinus, and in it Augustine found the answer to the Manichees" (Copleston, 1985, p. 85).

16 A concepção estoica sobre essa questão é distinta da de Aristóteles. Os estoicos podem aceitar que o nada não é algo, mas rejeitam que o oposto de algo seja exclusivamente o nada. Alguns deles estimam que os universais, por exemplo, não pertencem ao mundo ontológico do algo (TL), mas não são por isso nada. Eles os colocam antes no universo dos não algo, que não são nada, mas, sim, entidades formadas, entre outras coisas, pela mente. Cf. Long \& Sedley (1987, pp. 166-168). Por seu lado, Colish (1990, pp. 184-186) indica que a teoria do dizível ( $\lambda \in \kappa$ Kó $\nu$ ) estoica também teve uma influência marcante sobre a concepção agostiniana do mal como ausência ou privação. 
natureza inteiramente má. Nessa esfera, existe somente, segundo Agostinho, a má vontade humana ou algo parcialmente corrompido. Em suma, o mal não é somente contrário ao bem, como o indica Aristóteles nas "Categorias" 10 e 11, enfatizado por Plotino nas "Enéadas" I, 8, mas também é oposto à posse ou, como diz Abelardo, ao habitus.

Enfim habitus significa, na terceira divisão, as propriedades exteriores das coisas. Os exemplos que traz Abelardo correspondem àqueles apresentados por Aristóteles na seção das "Categorias" 9 sobre o haver ( $€ \chi \in L \nu$-habere), tomado de maneira específica. Nesse sentido preciso, habitus é, sem dúvida, uma maneira de ser adquirida. O Estagirita também retoma esse significado de habitus na sua descrição mais desenvolvida do pós-predicamento haver ( $€ \chi \chi \in L \nu)$, no último capítulo das "Categorias" 15. Ressaltamos que essa parte final desse tratado não corresponde exatamente àquela da categoria de haver no capítulo 9. Na realidade, a descrição, talvez incompleta, encontrada ali representa somente um dos casos de haver explicados por Aristóteles no capítulo 15.

$\mathrm{Na}$ descrição do pós-predicamento haver, existe igualmente, entre os diversos modos (тро́тоL-modi) apresentados, um caso que corresponde ao habitus como primeiro gênero da qualidade. Os outros modos desse mesmo pós-predicamento são ligados, por um lado, à categoria da quantidade. ${ }^{17}$ Por exemplo, ter ou haver $1,75 \mathrm{~m}$. Por outro lado, encontra-se um caso relacionado à categoria da relação como parte/todo. ${ }^{18}$ Assim, há o exemplo da mão e do pé, como partes de nós que temos ou possuímos (habere). Salientamos que não se trata, nesse último caso, do mesmo tipo de relação que o elo que existe entre o universal e o particular, que é, desta vez, de natureza essencial. Abelardo tem cuidado em distinguir a relação parte/todo da de inerência, que não é mais extrínseca. Por exemplo, o branco não pode ser separado do seu substrato sem afetar a própria substância, ao passo que um braço cortado não muda substancialmente o ser seccionado. Além dos casos que acabamos de apresentar, Aristóteles ainda menciona outros exemplos mais secundários que pertencem a esse pós-predicamento "haver". ${ }^{19}$

Na segunda passagem proveniente, nesta vez, da "Dialectica", Abelardo retoma essencialmente as mesmas distinções que as examinadas anteriormente na "Logica "Ingredientibus". Sob a rubrica De habere da seção intitulada De reliquis predicamentis (Das outras categorias), Abelardo indica, desde o 
início, que o termo habere, tomado em um sentido genérico, é equívoco e que Aristóteles enumera diferentes modos.

A palavra "habitus" teve várias significações entre os filósofos. De fato, pusemos que o habitus é, com a disposição, uma espécie da qualidade. Há igualmente o habitus < que se opõe à> privação, como a visão, cuja privação é a cegueira. Existe ainda o habitus tomado de maneira mais geral, que Aristóteles nomeou "haver", e do qual é preciso agora discutir. Seguindo Aristóteles, identificamos anteriormente muitos modos que dizem respeito a esse último tipo de habitus. Quanto ao número desses modos, deve ser atribuído, todavia, a Aristóteles, por causa do que dissemos anteriormente, ou, antes, a Boécio, que traduziu as Categorias, ou talvez a outro filósofo? Desde há muito tempo, existe uma grande dissensão sobre isso. ${ }^{20}$

É claro que se trata, nesse trecho, das mesmas três significações distintas descritas por Abelardo na "Logica 'Ingredientibus". Apesar disso, nosso protagonista acrescenta, na "Dialectica", que não há certeza acerca do autor na origem do número de modos encontrados na categoria de haver. Além de mostrar que Abelardo não possui o texto original grego, nem uma versão latina completa das "Categorias", o seu comentário indica que existe igualmente um debate importante entre os pensadores sobre essa questão há muito tempo. Notamos que Boécio retoma simplesmente, no seu “Comentário sobre as 'Categorias"' 9, as mesmas palavras que as mantidas por Aristóteles na categoria de haver.

Assinalamos, enfim, que Abelardo examina, no seu "Comentário sobre as 'Categorias' da 'Dialectica'”, somente as dez categorias (praedicamenta), o que inclui assim o habere, mas não distingue esse último do pós-predicamento homônimo. Para o Abelardo da "Dialectica", o termo "pós-predicamento" corresponde, antes, àquilo que vem, no "Organon", depois do tratado das "Categorias", aludindo assim a uma parte do conteúdo do "Peri hermeneias" ("De interpretatione"), que nomeia De uocibus significatiuis (Das palavras significativas). Quanto aos próprios pós-predicamentos de Aristóteles, Abelardo os analisa no seu "Comentário sobre os 'Tópicos' da 'Dialectica". Enfim, vimos que nosso protagonista trata, na "Logica 'Ingredientibus", dos pós-predicamentos na mesma ordem que a encontrada nas "Categorias" de Aristóteles.

20 Nossa tradução. "'Habitus' autem vocabulum multiplicem significationem apud philosophos habuit. Est enim habitus quem simul cum dispositione speciem qualitatis posuimus. Est etiam habitus privationis, ut visio, cuius est privatio cecitas. Est quoque Habitus generalissimum pro quo 'habere' Aristoteles posuit, de quo in presenti nobis est disserendum, cuius multos modos secundum Aristotilem supra posuimus; de qua tamen annumeratione mo < do $>$ rum, utrum Aristotili sit deputanda propter suprapositam causam, an potius Boetio, qui predicamenta transtulit, vel alicui fortasse philosophorum ascribenda, magna solet esse dissensio" (Petrus Abaelardus. "Dialectica", 1970, p. 109). 


\section{Virtude e habitus}

Em diferentes lugares da sua obra, Abelardo indica nitidamente que toma emprestado às "Categorias" de Aristóteles sua concepção da virtude como habitus. Que seja nos seus tratados de lógica, de ética, de epistemologia, de psicologia ou de teologia, nosso autor identifica as "Categorias" como sendo a fonte principal, à qual se refere para desenvolver sua teoria da virtude. Vejamos o que afirma sobre isso em alguns dos seus textos. Primeiro, na sua ética intitulada "Dialogo entre um filósofo, um judeu e um cristão":

Filósofo: A virtude, dizem eles (os filósofos), é o melhor habitus do espírito [...]. De fato, chamamos de habitus o que Aristóteles distinguiu nas Categorias (VIII) quando reuniu habitus e disposição na primeira espécie da qualidade. O habitus é, portanto, uma qualidade da coisa que não lhe é naturalmente inata (insita), mas conquistada (conquisita) por um esforço deliberado e é dificilmente passível de alteração. [...] Afirma (Boécio) também que toda virtude é dificilmente modificável quando explica, no tratado mencionado acima sobre a qualidade, que Aristóteles coloca ciências e virtudes entre os habitus. Diz (Boécio): "A não ser que seja difícil de alterar, não é uma virtude". ${ }^{21}$

Antes de examinar quais são as principais características da natureza da virtude segundo Abelardo, vejamos outro extrato sobre o mesmo tema tirado, desta vez, do "Sic et non" 144.

Aristóteles no seu tratado sobre a qualidade: O habitus difere da disposição, porque é mais permanente e duradouro. Tais são as ciências e as virtudes. De fato, a ciência parece $<$ pertencer $>$ a essas coisas permanentes, que são dificilmente movidas, como se alguém usava seu saber inteiramente ou em parte, a não ser que uma grande perturbação aconteça fortuitamente por causa de uma doença ou de algo parecido. Da mesma maneira, as virtudes, como a justiça ou a castidade e outra coisa desse gênero, não parecem ser facilmente mudadas, nem modificadas. ${ }^{22}$

21 Nossa tradução. "PHILOSOPHUS. Virtus, inquiunt, est habitus animi optimus [...]; habitum vero hunc dicimus, quem Aristotiles in Categoriis distinxit, cum in habitu et dispositione primam qualitatis speciem comprehendit. Est igitur habitus qualitas rei non naturaliter insita, sed studio ac deliberatione conquisita et difficile mobilis. [...] Hic etiam virtutem omnem difficile mobilem esse asserens, cum in predicto qualitatis tractatu Aristotilem exponeret scientias et virtutes inter habitus collocantem: 'Virtus enim', inquit (Boethius), 'nisi difficile mutabilis non est'” (Petrus Abaelardus. "Dialogus", 1970, pp. 115-116).

22 Nossa tradução. "Aristoteles in tractatu Qualitatis: Differt autem habitus a dispositione, quod permanentior et diuturnior est. Tales vero sunt scientiae et virtutes. Scientia enim videtur permanentium et eorum quae difficile moventur, ut si perfecte qui vel mediocriter scientiam sumat, nisi forte grandis permutatio facta sit vel ab aegritudine vel ab aliquo huiusmodi. Similiter autem et virtus ut justitia vel castitas et singula talium non videntur facile posse moveri neque permutari". Capitulum 144 (Quod peccator sit ille tamen qui assiduus est in peccatis, et contra). Abaelardus (1855, p. 1591A). Cf. Peter Abailard (1977, p. 497). 
Encontramos, nesses dois trechos, as principais particularidades da virtude descritas por Aristóteles nas "Categorias" 8, assim como outras características, que não estão presentes. Lembramos que, na exceção de uma parte dos tratados conhecidos sob o nome de logica uetus, Pedro não tem acesso ao resto da obra do Estagirita, inclusive as éticas, a "Metafísica" e a "Retórica", nas quais as descrições do habitus são bastante detalhadas. Por enquanto, vejamos o que pode conhecer Abelardo nas "Categorias" sobre a virtude.

Em primeiro lugar, nosso autor afirma que, na qualidade de habitus, a virtude é adquirida (conquisita) através de um esforço deliberado e racional, daí seu mérito. Portanto, não está naturalmente (insita) em nós. Quanto a Aristóteles, vejamos o que diz sobre isso:

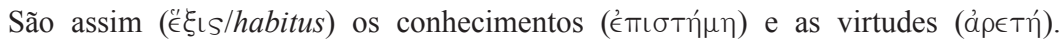
Pois o conhecimento parece ser uma coisa permanente e difícil de mudar (mesmo que alguém o adquira ( $\left.\lambda \alpha \beta_{\eta}\right)$ moderadamente), a não ser que ocorra uma grande alteração, por doença ou por alguma outra coisa deste tipo. ${ }^{23}$

A segunda característica da virtude como habitus, levantada por Abelardo, também se encontra nas "Categorias" e diz respeito à sua estabilidade e sua quase permanência. Na passagem que acabamos de citar, o Estagirita assinala as duas mesmas distinções, afirmando que os saberes ou conhecimentos e as virtudes são duradouros e difíceis de ser movidos. Na verdade, parece que

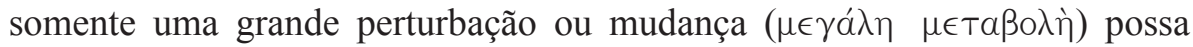
abalar esses habitus. O corolário desse traço marcante é que o habitus não é uma disposição (dispositio). Portanto, a virtude como habitus também não é uma disposição $(\delta \iota a ́ \theta \in \sigma \iota s)$. De fato, a natureza quase permanente e duradoura do habitus distingue-se da constituição da disposição que, ao inverso, é pouco estável e mais efêmera. Os dois elementos do primeiro gênero da qualidade assemelham-se, contudo, devido a seu caráter adquirido, como o mostra Abelardo na sua "Ethica sive Scito teipsum".

Pois como os filósofos mantiveram, nunca se deve dizer ter uma virtude, a não ser que seja um habitus ótimo da mente ou um habitus de uma mente bem constituída. Mas o que chamaram de habitus ou disposição? Aristóteles cuidadosamente os distinguiu na primeira espécie da qualidade, ao ensinar que são chamadas de habitus ou de disposições essas qualidades que não estão naturalmente (natutaliter) in nós, mas que vêm pela nossa aplicação. São habitus, disse ele, se forem difícil de mudar, tais 
como as ciências ou as virtudes. Mas são disposições, ao inverso, se forem facilmente mutáveis. $^{24}$

Nas "Categorias" 8, Aristóteles também afirma que o habitus (" $\xi \xi_{\mathrm{LS}}$ ) e a disposição $(\delta\llcorner a ́ \theta \in \sigma \iota s)$ distinguem-se simplesmente pela duração e pela permanência. Ele conclui sobre isso: "Por conseguinte, um estado difere de uma disposição por esta ser fácil de mudar, enquanto aquele é mais durável e mais difícil de mudar". ${ }^{25}$

Os exemplos de disposições dados por Aristóteles são a doença e a saúde, assim como o calor e o frio, que são, de certa maneira, adquiridos. Portanto, o homem transita, por exemplo, do estado de saúde ao de doença, e viceversa, em pouco tempo. Agora, as disposições apresentadas pelo Estagirita nas "Categorias" levantam algumas dificuldades. Os casos expostos dizem respeito somente a corpos e não há nenhum exemplo de disposição mais inteligível. O resultado é que são comparadas coisas distintas na oposição entre o habitus e a disposição. Além disso, parece bastante claro que um dos dois elementos dos pares de opostos que compõem as disposições deva ser mais permanente e durável que o outro. Por exemplo, no par saúde/doença, um dos dois componentes deve, em princípio, ser mais duradouro que o outro. De fato, não passamos constantemente de um estado de saúde a um de doença, ambos sendo mutáveis. Entre o calor e o frio, também devem existir vários graus intermediários, deixando difícil de identificar exatamente o estado quente ou frio.

Deixando essas dificuldades de lado, o fato é que existem, nos textos de Abelardo citados acima, outras características da virtude que não se encontram nas "Categorias". Primeiro, nosso protagonista enuncia claramente que a virtude não é qualquer tipo de habitus, mas, sim, um habitus excelente (habitus optimus) ${ }^{26}$ Além disso, é acrescentado que esse habitus excelente, que constitui a virtude, não é corpóreo, mas antes do espírito ou da mente (habitus animi optimus-habitus mentis optimus). ${ }^{27} \mathrm{O}$ próprio Aristóteles não descreve nesses termos a virtude ou o saber, pelo menos nas "Categorias", ainda que seja bastante claro que esses habitus são excelentes e pertencem à alma.

24 Nossa tradução. "Vt enim philosophis placuit, nequaquam uirtus in nobis dicenda est, nisi sit habitus mentis optimus, siue habitus bene constitute mentis. Quid uero habitum uel dispositionem dixerint, Aristoteles in prima specie qualitatis diligenter distinxit, docendo uidelicet eas qualitates que non natutaliter nobis insunt, set per applicacionem nostram ueniunt, habitus vel disposiciones uocari. Habitus quidem, si sint difficile mobiles, quales, inquit, sunt sciencie uel uirtutes. Disposiciones uero, si e contra fuerint facile mobiles" ("Peter Abelard's Ethics”, 1971, p 128). Cf. Petrus Abaelardus. "Dialectica", 1970, p. 93.

25 Aristóteles. "Categorias" 8, 9a 8-10. In: Aristóteles (1995, p. 53).

26 Cf. Petrus Abaelardus. "Dialogus" (1970, pp. 115-116); "Peter Abelard's Ethics” (1971, p. 128).

27 Cf. "Peter Abelard's Ethics" (1971, p. 128). 
Ao início da sua "Ethica", Abelardo distingue as qualidades corpóreas das da alma. Além disso, discerne as qualidades mentais, que não pertencem ao domínio da ética, das que fazem parte dele. ${ }^{28}$ Por exemplo, uma mente rápida ou uma boa memória são manifestamente qualidades da alma, mas não são por isso habitus, mesmo que sejam duradouras e quase permanentes. Essas qualidades são antes aptidões, como diria o Aristóteles das "Categorias" 8, e deveriam estar classificadas entre as qualidades do segundo gênero

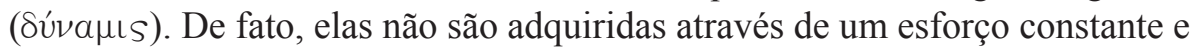
permanente, mas se encontram naturalmente em nós. Portanto, essas aptidões não ocasionam o mérito e são, por esse motivo, excluídas da esfera moral. ${ }^{29}$

Se a característica da virtude como habitus excelente da mente (habitus animi/mentis optimus) não vem explicitamente do Aristóteles das "Categorias", então donde vem? Quem são esses filósofos (philosophi) aos quais Abelardo se refere nos trechos apresentados acima? Seguindo a ordem cronológica, encontramos, para começar, essa particularidade entre os latinos em Cícero. No "De inuentione", ao qual Abelardo tinha diretamente acesso, ${ }^{30}$ Cícero afirma nitidamente esse traço específico do habitus. Indicamos a seguir a definição da virtude proposta pelo orador romano no contexto de uma discussão bem estoica sobre o honesto.

O que se procura por si mesmo, <que seja $>$ inteiramente ou, de algum modo, em parte, chamar-nos-emos honesto (honestum). Por isso, como é dividido em duas partes, ora simples, ora misto, consideramos primeiro a simples. ${ }^{31}$ Em esse gênero, tudo <que tem> uma única natureza e um mesmo nome é, portanto, compreendido na virtude. Pois a virtude é um habitus do espírito (animi habitus), conforme a natureza e a razão. Assim, quando serão conhecidas todas as suas partes, será considerado o valor inteiro da honestidade pura. ${ }^{32}$

28 Cf. "Peter Abelard's Ethics" (1971, pp. 3-5).

29 Cf. "Glossae super Predicamenta Aristotelis". In: Peter Abaelards Philosophische Schriften (1919-1927, pp. 227-228).

30 "PHILOSOPHUS. Sic profecto nostris visum est maioribus, sicut in secundo Rethorice sue M. Tullius plenius exsequitur" (Petrus Abaelardus. "Dialogus", 1970, p. 105).

31 Cícero indica anteriormente na mesma obra ("De invent." II, LII, 157-158) que devem ser procurados, em relação ao honesto e ao útil, três tipos de coisas. Em primeiro lugar, a virtude, o saber e a verdade, que pertencem ao domínio do honesto, devem ser buscados por si mesmos. Em seguida, a riqueza e outros bens parecidos têm de ser procurados não por causa da sua natureza, mas, sim, em razão da sua utilidade e do seu benefício. Enfim, há coisas que participam das duas primeiras categorias, como a amizade e a boa reputação, que também devem ser buscadas por si mesmas, devido a sua natureza e a sua utilidade. $\mathrm{O}$ que deve ser evitado são as coisas que se opõem a essas três esferas, ou seja, o que é indigno (turpitudo) e inútil. Em relação à passagem de Cícero, as coisas simples (simplex) são, portanto, da primeira e da segunda categoria, sendo respectivamente do honesto e do útil, ao passo que as coisas mistas ou complexas pertencem à última classe e também fazem parte do honesto.

32 Nossa tradução. "Quod aut totum aut aliqua ex parte propter se petitur, honestum nominabimus. Quare, cum ejus duae partes sint, quarum altera simplex, altera juncta sit, simplicem prius consideremus. Est igitur in eo genere omnes res una vi atque uno nomine amplexa virtus. Nam virtus est animi habitus naturae 
Nesse último trecho, a virtude é claramente identificada a um habitus mental. Em duas outras passagens do mesmo tratado, Cícero também afirma:

Chamamos habitus do espírito (habitum animi) ou do corpo uma perfeição constante e absoluta em alguma coisa, como a virtude, a posse de uma arte, qualquer ciência ou até certa vantagem corpórea não dada pela natureza, mas gerada pela aplicação e pelo trabalho. ${ }^{33}$

Um pouco mais adiante, reitera: "Já que o habitus consiste em certo acabamento perfeito e constante do espírito (animi) ou do corpo, cujo gênero é a virtude, o saber e aquilo que é contrário [...]". ${ }^{34}$

Nesses três extratos do "De inuentione" de Cícero, encontramos, portanto, a concepção segundo a qual a virtude não é só um habitus do espírito, mas também a ideia implícita de que se trata de um habitus excelente da mente. De fato, ao usar expressões como "perfeição constante e absoluta" (perfectio constans et absoluta) e "acabamento perfeito e constante" (absolutio perfecta et constans), o orador deixa entender que o habitus mental em questão é, segundo as palavras de Abelardo, algo "ótimo" e pertence a uma "mente bem constituída". Todavia, não podemos inferir, a partir daí, que Abelardo pede emprestado diretamente a Cícero essas características essenciais do habitus, mesmo que se encontrem em um mesmo contexto de uma definição da virtude. As expressões usadas por cada um dos dois autores são bastante diferentes e Abelardo não se refere explicitamente a Cícero, apesar de ter acesso ao "De inventione".

Antes de examinar outra autoridade possível, em que Abelardo busca diretamente suas informações acerca do habitus, queremos fazer duas observações sobre o que acabamos de considerar. Primeiro, o próprio Cícero não indica explicitamente no "De inuentione" a fonte à qual se refere para descrever a virtude, mas o contexto no qual aparece a sua definição é claramente estoico. Não há dúvida de que a explicação do honesto (honestum) e do útil ou da vantagem (utile-commodum) corresponde ao que os estoicos antigos

modo atque rationi consentaneus. Quamobrem omnibus ejus partibus cognitis tota vis erit simplicis honestatis considerata" ("De inventione" II, LIII, 159. In: Cicéron, 1932, p. 256).

33 Nossa tradução. "Habitum autem appellamus animi aut corporis constantem et absolutam aliqua in re perfectionem, ut virtutem aut artis alicujus perceptionem aut quamvis scientiam et item corporis aliquam commoditatem non natura datam, sed studio et industria partam" ("De inventione", I, XXV, 36. In: Cicéron, 1932, p. 54).

34 Nossa tradução. "Habitus autem quoniam in aliqua perfecta et constanti animi aut corporis absolutione consistit, quo in genere est virtus, scientia et quae contraria sunt [...]" ("De inventione” II, IX, 30. In: Cicéron, 1932, p. 148). 


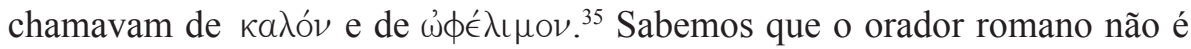
stricto sensu um pensador do Pórtico, mas que apresenta a filosofia estoica em detalhes em uma boa parte da sua obra. Além disso, os pensadores da Stoa também mantêm que a natureza da virtude ${ }^{36}$ consiste em uma perfeição (' $\mathcal{E} v$

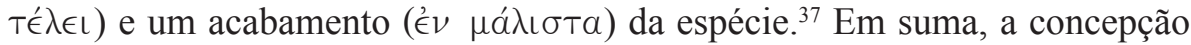
da virtude como habitus de Cícero, tal como apresentada no "De inuentione", é claramente de inspiração aristotélica, mas, o que não é contraditório, o contexto no qual se manifesta parece, antes, estoico. Como veremos mais adiante, a compreensão da virtude por parte das duas escolas filosóficas em estudo não é incompatível.

Em segundo lugar, notamos que Cícero afirma, em uma das passagens citadas acima, que esse habitus do espírito não é dado naturalmente, mas que é gerado ou adquirido pela aplicação e pelo esforço (studio et industria partam), expressões igualmente retomadas em boa parte por Abelardo, quando descreve a virtude. Na ocasião, esse último indica que ela é "conquistada por um esforço deliberado" (studio ac deliberatione conquisita) e que "vêm pela nossa aplicação" (per applicationem nostram ueniunt). ${ }^{38}$ Vimos que essa importante característica do habitus já é exposta por Aristóteles nas "Categorias". ${ }^{39}$ Chamamos a atenção de que Agostinho retoma palavra por palavra e integralmente, no seu "De diversis quaestionibus LXXXIII", ${ }^{40}$ o primeiro trecho do "De inuentione", que citamos acima. ${ }^{41}$ Abelardo tinha igualmente acesso diretamente a esse tratado do Bispo de Hipona. Notamos enfim que Sêneca usa o mesmo tipo de expressões que Cícero para descrever a virtude nas suas "Cartas a Lucílio", as quais também eram acessíveis a nosso protagonista. $^{42}$

Passamos agora a Boécio, cujas traduções latinas e comentários são usados por Abelardo para descrever, entre outras coisas, a virtude como habitus. Vimos anteriormente que nosso autor se refere diretamente a ele em trechos citados acima e o menciona de novo numa outra passagem do capítulo 144 do "Sic et non," intitulado "O pecador é aquele que é assíduo nos seus

35 Cf. Long \& Sedley (1987, pp. 200-201; 367-373).

36 Voltamos mais adiante sobre essa questão da natureza da virtude para os estoicos, que modificam o vocabulário de Aristóteles, apesar de se referir a uma mesma realidade.

37 Cf. Long \& Sedley (1987, p. 286).

38 Cf. Petrus Abaelardus. "Dialogus" (1970, pp 115-116). "Peter Abelard's Ethics" (1971, p. 128). Ver também Petrus Abaelardus. "Dialectica" (1970, p. 93).

39 Cf. Aristóteles. "Categorias" 8, 8b 29-32.

40 Cf. "De diversis quaestionibus LXXXIII", Quaestio 31 (Sententia Ciceronis, quemadmodum virtutes animi ab illo divisae ac definitae sint).

41 Cf. "De inventione" II, LIII, 159.

42 Cf. "Cartas a Lucílio" 95. Ver também Hamelin (1996, pp. 118-132). 
pecados, ou não?” (“Quod peccator sit ille tamen qui assiduus est in peccatis, e contra"):

Boécio em seu comentário sobre essa passagem: ${ }^{43}$ a não ser com dificuldade, a virtude não é mutável. Aquele que julga uma vez de maneira justa não é alguém justo, nem é adúltero aquele que comete uma vez adultério, mas $<$ é o caso $>$ quando permanecem essa vontade e esse pensamento (de julgar de maneira justa e de cometer adultério). De fato, Aristóteles não pensa, como Sócrates, que as virtudes são saberes. O mesmo (Boécio) no seu livro das divisões: ${ }^{44}[\ldots]$ O termo é convertido assim: a virtude é um habitus ótimo da mente; de forma recíproca, um habitus ótimo da mente é a virtude. Do mesmo modo, o mesmo (Boécio) no seu segundo <livro> dos tópicos: ${ }^{45}$ Seja a questão, <a saber $>$, se a virtude é um habitus de uma mente bem constituída. A questão da definição etc. ${ }^{46}$

Nesse extrato, Abelardo glosa o "De diuisione" e o "De differentiis topicis" de Boécio, nos quais se encontram as duas mesmas expressões usadas no seu tratado "Ethica sive Scito teipsum", a saber, respectivamente, "a virtude é um habitus ótimo da mente" (habitus mentis optimus uirtus est) e "a virtude é um habitus de uma mente bem constituída" (uirtus mentis bene constitutae sit habitus). Nesse caso, não há dúvida que nosso autor toma emprestado ao Romano essas duas fórmulas. Ora, a questão permanece: onde Boécio pega essas locuções para definir a virtude? Não há indicação sobre isso por parte dele, mas é possível, como vimos, que Cícero o inspirou, já que verossimilmente cunhou o termo habitus para traduzir a " $\epsilon$ $\xi \mathrm{s}$, tal como descrita por Aristóteles nas "Categorias" $8 .{ }^{47}$ Por outro lado, Abelardo também pode ter sido influenciado por Sêneca ou Agostinho, que retomam o essencial do pensamento do orador sobre o assunto. ${ }^{48}$

É possível ainda ter alguma dúvida acerca da influência real exercida pelos estoicos sobre a concepção abelardiana da virtude como habitus excelente da mente, já que o essencial das expressões usadas por Abelardo para descrevê-la

43 Boethius. In: "Categorias Aristotelis" iii. In: Boethius (1847, p. 242B-C).

44 Boethius. "De divisione". In: Boethius (1847, p. 885B).

45 Boethius. "De differentiis topicis" ii. In: Boethius (1847, p. 1188C).

46 Nossa tradução. "Boethius in commento super hunc locum: Virtus enim nisi difficile mutabilis non est. Neque enim qui semel iuste iudicat iustus est, neque qui semel adulterium facit est adulter, sed cum ista uoluntas cogitatioque /498/ permanserit. Aristoteles enim uirtutes non putat scientias, ut Socrates. Idem in libro divisionum: Ut in se ipsa diuisio sicut terminus conuertatur. Conuertitur enim terminus sic: uirtus est mentis habitue optimus; rursus, habitus mentis optimus uirtus est. Item idem in secundo topicorum: Sit quaestio an uirtus mentis bene constitutae sit habitus. Quaestio de diffinitione etc". Peter Abailard (1977, pp. 497-498). Cf. Abaelardus (1855, p. 1591A-B).

47 "Nous sommes enclins à penser que Cicéron est sinon le premier de tous les philosophes latins, du moins le premier penseur important d'expression latine à traduire le grec hexis par le terme latin habitus" (Hamelin, 1996, p. 103).

48 Hamelin (1996, pp. 118-132; 162-205). 
encontra-se, como vimos, nos tratados de Boécio. Todavia, uma coisa parece certa. Aristóteles manteria essas características do habitus de ser, ao mesmo tempo, espiritual e perfeito, pelo menos quando se trata da virtude. ${ }^{49}$ Mas, também, não se pode esquecer o contexto nitidamente estoico, no qual aparece a discussão sobre a virtude, notadamente no "Dialogus", onde nosso autor refere-se diretamente ao "De inventione" (II, 52) de Cícero na sua análise do honesto (honestum) e do útil (utilis). ${ }^{50}$ Enfim, não há dúvida a respeito da filiação estoica da expressão usada pelo orador romano para definir, como vimos, a virtude como "habitus do espírito conforme a natureza e a razão" (animi habitus naturae modo atque rationi consentaneus). ${ }^{51}$

Se existe uma noção distintamente estoica, até mesmo especificamente da escola do Pórtico, é sem dúvida nenhuma a da virtude em conformidade com a

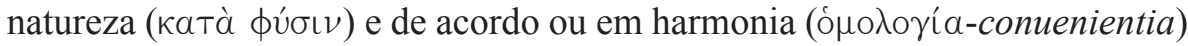
com a razão. Encontram-se vários fragmentos, confirmando o domínio estoico dessa concepção. ${ }^{52} \mathrm{O}$ comentador contemporâneo Kidd afirma sobre isso:

[...] as right reason is identical with God [...] a man will never make sufficient progress

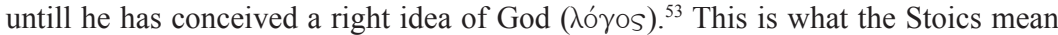

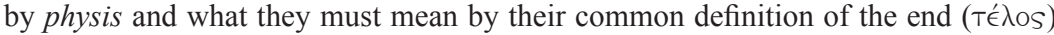

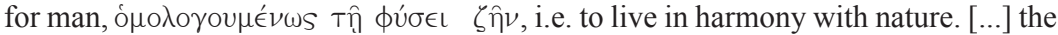
end ( $T \in \dot{\ell} \mathrm{OS}$ ) as before is to live in harmony with nature, which is precisely to live in accordance with virtue $[\ldots] .^{54}$

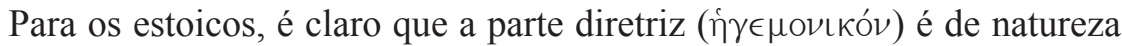
psíquica, e que a virtude constitui, uma vez adquirida, um dos seus componentes em potência. ${ }^{55}$ Além disso, já que as virtudes são, para esses pensadores, estritamente saberes ou conhecimentos, o caráter racional delas é conforme

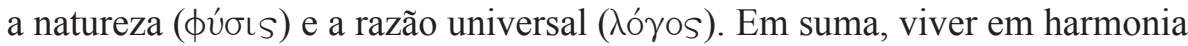
com a natureza é, portanto, viver de acordo com a virtude.

Agostinho assume essa tese estoica da parte diretriz, ${ }^{56}$ acrescendo não somente os julgamentos morais, mas também as paixões ou afecções, que são, ao inverso da concepção aristotélica, todas negativas. Por seu lado, Abelardo recupera, por meio do Filósofo do seu "Dialogus", a visão da Stoa, segundo

49 Cf. Aristóteles. "Categorias" 8 in toto.

50 Cf. Petrus Abaelardus. "Dialogus" (1970, p. 105).

51 Cf. Cicero. "De inventione" II, LIII, 159.

52 Cf. Long \& Sedley (1987, pp. 349-355; 389-394).

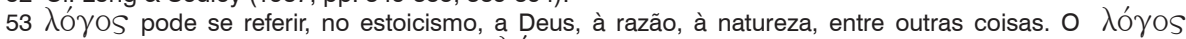
macrocósmico inclui, em certo sentido, o $\lambda$ ó $\gamma O S$ microcósmico ou a razão do homem.

54 Kidd (1971, pp. 158-162).

55 Plutarque. "De la vertu morale" (441B-C). In: Long \& Sedley (1987, pp. 373-374).

56 Cf. Colish (1990, p. 237). 
a qual a virtude como habitus é conforme a natureza e a razão. Ele mantém particularmente que o filósofo obedecia às leis naturais de acordo com a razão antes do advento da Escritura e que deve continuar a exercer essa faculdade racional mesmo após a Revelação.

Filósofo: [...] é o papel próprio dos filósofos buscarem a verdade por meios racionais e seguir, para todas as coisas, não a opinião dos homens, mas a direção da razão. [...] Logo depois de ter sido instruído ali (em nossas escolas), tanto quanto podia, sobre o bem supremo e o mal supremo e sobre o que faz o homem beato ou miserável, examinei cuidadosamente as diferentes escolas religiosas perto de mim, entre as quais o mundo está agora dividido. Depois de ter examinado e comparado todas elas, decidi seguir o que é mais conforme a razão ${ }^{57}$. [...] Daí vossa predicação, a saber, a cristã, é altamente recomendada, pois conseguiu converter à fé aqueles que mais se apoiavam e abundavam em razões, a saber, os imbuídos nos estudos das artes liberais e os armados de razões. ${ }^{58}$

No mesmo tratado, nosso autor também se refere à lei natural que o filósofo deve seguir.

Filósofo: É certo que antes da transmissão da lei ou da observância dos sacramentos legais, a maioria das pessoas, contente com a lei natural [...], cumpriu a justiça [...]. [...] Assim, quando devemos viver com os outros, temos também de nos submeter a suas instituições que mencionamos, assim como obedecemos aos direitos naturais. ${ }^{59}$

É claro que tanto os platônicos quanto os aristotélicos também podem defender teses similares. Mas a ideia de observar as leis naturais e obedecer ao direito igualmente natural, assim como seguir os preceitos da razão, mesmo depois do advento da lei mosaica, são temas predominantes no sistema filosófico estoico de todos os períodos confundidos, que seja no estoicismo antigo, médio ou imperial.

57 Segundo o tradutor Payer, Abelardo seguiria aqui a definição ciceroniana da virtude tal como encontrada no "De inventione" II, LIII, 159. Concordamos em boa parte com esse comentário. Cf. Abelard (1979, p. 21, nota 4).

58 Nossa tradução. "PHILOSOPHUS. [...] quoniam id suum est philosophorum rationibus veritatem investigare et in omnibus non opinionem hominum, sed rationis sequi ducatum". [...] "Hic de summo bono et de summo malo et de his, que vel beatum hominem vel miserum faciunt, quoad potui, instructus statim apud me diversas etiam fidei sectas, quibus nunc mundus divisus est, studiose scrutatus sum, et omnibus inspectis et invicem collatis illud sequi decrevi, quod consentaneum magis sit rationi". [...] "Unde maxime vestra, id est xristiana, predicatio commendatur, quod eos ad finem convertere potuit, qui rationibus plurimum nitebantur et habundabant, omnium videlicet liberalium artium studiis inbuti, rationibus armati" (Petrus Abaelardus. "Dialogus”, 1970, pp. 41-42, 91).

59 Nossa tradução. "Constat ante ipsam legis traditionem vel sacramentorum legalium observationes plerosque lege naturali contentos [...] iustitiam coluisse [...]". [...] "Unde fit, ut, cum quibuscumque vivendum est nobis, eorum quoque instituta, que diximus, sicut et naturalia iura teneamus" (Petrus Abaelardus. "Dialogus", 1970, pp. 53, 125). 


\section{Conclusão}

A nossa análise mostra que a definição da virtude de Abelardo é, para o essencial, de natureza aristotélica. De maneira mais precisa, vem diretamente das "Categorias" do Estagirita, traduzidas por Boécio. Os comentários e as monografias deste último autor também exercem um papel determinante na concepção abelardiana da virtude.

Vimos que Cícero retoma em parte a característica fundamental dessa explicação quando indica, no "De inventione", que a virtude é um habitus do espírito. Por outro lado, Agostinho, que influenciou bastante a ética de Abelardo com a sua teoria, entre outras coisas, da intenção, retoma literalmente a definição ciceroniana encontrada no "De inventione" numa obra de juventude intitulada "De diversis quaestionibus LXXXIII". ${ }^{60}$

Nessa altura, é importante notar que os estoicos antigos não usam o termo ${ }^{\prime \prime} \xi$ ıs, traduzido em latim por habitus, para descrever a virtude, mas, sim, $\delta \iota a ́ \theta \in \sigma \iota s$, que os latinos rendem por dispositio. Para os defensores do Pórtico, $\epsilon^{\prime \prime} \xi$ เS refere-se a outras realidades; usam antes $\delta \iota \alpha ́ \theta \in \sigma ı s$ para definir a virtude. Nesse caso, a virtude como disposição mantém o essencial das características aristotélicas, tratando-se de uma natureza estável, imutável, quase permanente e adquirida. ${ }^{61}$

Abelardo tem acesso aos tratados em questão, nos quais se encontra a concepção da virtude de Aristóteles, assim como os acréscimos de natureza estoica feita por Cícero. Observamos no presente estudo que nosso protagonista recupera, notadamente no "Dialogus", vários desses componentes do Pórtico, como a identificação explícita da virtude com o honesto ou a perfeição ${ }^{62} \mathrm{e}$, sobretudo, com a ideia de que ela é conforme a natureza e a razão. Nesses casos, trata-se da concepção do Filósofo do tratado, a qual não corresponde necessariamente ao próprio ponto de vista do autor, apesar do fato de que essas características estoicas não se opõem verdadeiramente à visão de Aristóteles.

Sem rejeitar inteiramente a análise estoica, Abelardo aparentemente prefere, afinal de contas, a posição aristotélica para descrever a natureza da virtude. É o que se destaca no mesmo "Dialogus", quando nosso autor expõe as quatro virtudes cardeais sob a influência parcial do "De inventione" (II,

60 Cf. "De diversis quaestionibus LXXXIII", Quaestio 31 (Sententia Ciceronis, quemadmodum virtutes animi ab illo divisae ac definitae sint).

61 Cf. Simplicius. In Ar. Cat. 237, 25-238, 20. In: Long \& Sedley (1987, p. 286). Plutarch. Virt. Mor. 440E-441D. In: Long \& Sedley (1987, pp. 373-374).

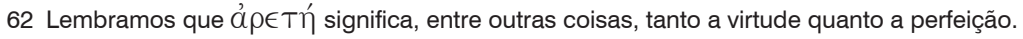


LIII, 160-164) de Cícero. ${ }^{63}$ Nessa ocasião, Abelardo não retoma a concepção estoica, segundo a qual todas as virtudes são conhecimentos ou saberes. De acordo com a escola do Pórtico, que dá assim continuidade à visão socrático-platônica, todas as virtudes reduzem-se a uma única, isto é, um

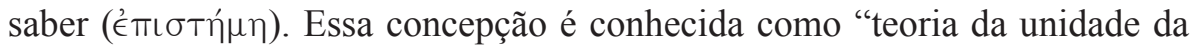
virtude". ${ }^{64}$ Agostinho parece sofrer essa influência, ao circunscrever todas as virtudes à única caridade (charitas). Por sua vez, Abelardo é muito cauteloso, distanciando-se dessa teoria. Retomando a tese de Aristóteles, defende antes que as virtudes cardeais são o resultado da prática e da aplicação, salvo a prudência ( $\phi \rho o ́ v \eta \sigma ı s-p r u d e n t i a)$ e suas subespécies, que constituem saberes. Esse tema é esclarecido na sua "Logica "Ingredientibus":

É conhecido que Aristóteles distingue os saberes das virtudes, ao passo que Sócrates coloque a prudência como a quarta espécie da virtude. Daí Boécio diz no seu Comentário: "Aristóteles declara na sua Ética que as virtudes não são saberes, como em Sócrates, mas, sim, habitus". ${ }^{65}$ Mas Aristóteles separa nitidamente o saber da virtude, pois o saber consiste no discernimento e na cognição do que deve ou não ser feito. Por outro lado, a virtude consiste na execução do que o saber percebe e a razão convence. Se não for o caso, a virtude seria sem mérito, ao dizer que é um saber. ${ }^{66}$

Ainda que o início desse trecho seja enganador, já que os saberes também são, segundo Aristóteles, habitus, Abelardo pretende dizer aqui que as virtudes morais, como a justiça, a temperança, a coragem e suas subespécies respectivas, não são saberes ou conhecimentos, mas, sim, habitus resultantes da prática e da aplicação. Ao inverso, a prudência, como os outros conhecimentos, constitui antes uma virtude dianoética ou intelectual, embora também seja um habitus. Como o confirma o resto da citação, é graças ao esforço fornecido pela prática para adquirir as virtudes morais que podemos recolher o mérito. Nesse ponto decisivo sobre a natureza da virtude, Abelardo não hesita a defender a concepção aristotélica, em detrimento da dos estoicos. Em suma, ao descrever a virtude, Abelardo navega em dois universos teóricos distintos, nos quais o contexto e algumas descrições são, por vezes, claramente

63 Cf. Petrus Abaelardus. "Dialogus” (1970, pp. 117-120).

64 Essa teoria não deve ser confundida com a doutrina da conexão das virtudes defendida, por exemplo, por Aristóteles.

65 Boethius. "In Categorias Aristotelis" iii. In: Boethius (1847, p. 242C).

66 Nossa tradução. "Nota, quod Aristoteles scientias dividat a virtutibus, cum Socrates ponat prudentiam quartam speciem virtutis. Unde Boethius in Commento: 'Aristoteles, inquit, virtutes non scientias, ut Socrates, sed habitus in Ethicis suis esse declarat'. Bene autem Aristoteles scientiam a virtute dividit, quia scientia in discretione et cognitione, quid faciendum sit, quid non, consistit, virtus autem in executione eius quod scientia percepit et ratio persuadet, alioquin virtus sine merito esset, si videlicet scientiam virtutem diceremus" ("Glossae super Predicamenta Aristotelis". In: Peter Abaelards Philosophische Schriften, 19191927, pp. 227-228). 
estoicos. Todavia, não hesita em considerar o essencial dessa qualidade sob a perspectiva aristotélica.

\section{Referências}

\section{Obras de Petrus Abaelardus}

ABAELARDUS. "Sic et non". In: Patrologiae Cursus completus (PL). Tomus 178. Ed. J.P. Migne. Paris: J. P. Migne Editorem, 1855.

ABELARD. "Dialogue of a Philosopher with a Jew and a Christian". Translated by P. J. Payer. Toronto: Pontifical Institute of Medieval Studies, 1979.

MINIO-PALUELLO, L. "Twelfth-Century Logic. Texts and Studies II. Abaelardiana Inedita". Roma: Edizioni di storia e litteratura, 1958.

"Peter Abaelards philosophische Schriften. I. Die Logica 'Ingredientibus"”. Ed. B. Geyer. BGPTM XXI.1-3. Münster i. W.: Aschendorffschen Verlagsbuchhandlung, 1919-1927.

"Peter Abaelards philosophische Schriften. II. Die Logica 'Nostrorum petitioni sociorum"”. Ed. B. Geyer. BGPTM XXI. 4. Münster i. W.: Aschendorffsche Verlagsbuchhandlung, 1933.

PETRUS ABAELARDUS. "Dialectica". Ed. L.M. de Rijk. 2ª ed. Assen: Van Gorcum \& comp. N.V.-Dr. H.J. Prankke \& H.M.G. Prakke, 1970.

PETRUS ABAELARDUS. "Dialogus inter Philosophum, Iudaeum et Christianum". Textkritische Edition von Rudolf Thomas. Stuttgart-Bad Cannstatt: Friedrich Frommann Verlag, 1970.

PETER ABAILARD. "Sic et Non: A Critical Edition". Ed. B. B. Boyer \& R. P. MacKeon. Chicago: University of Chicago Press, 1977.

"Peter Abelard's Ethics". Ed. D. E. Luscombe. Oxford: Clarendon Press, 1971.

PIETRO ABELARDO. "Scritti filosofici”. Ed. M. Dal Pra. Roma/Milano: Fratelli Bocca Editori, 1954.

\section{Outras obras}

ARISTÓTELES. "Categorias". Tradução, introdução e comentário de Ricardo Santos. Porto: Porto Editora, LDA, 1995.

BOETHIUS. In: "Patrologiae Cursus completus" (PL). Tomus 64. Ed. J. P. Migne. Paris: J. P. Migne Editorem, 1847.

CICÉRON. "De l'invention (De inventione)". Ed. Bornecque. Paris: Librairie Garnier Frères, 1932.

COLISH, M.L. "The Stoic Tradition From Antiquity to The Early Middle Ages. II. Stoicism in Christian Latin Thought Through the Sixth Century". Leiden: E.J. Brill, 1990.

COPLESTON, F. “A History of Philosophy". Vol. II "Augustine to Scotus". NewYork: Image Books Doubleday, 1985.

HAMELIN, G. "L'origine de la doctrine de la vertu comme habitus chez Pierre Abélard". Trois-Rivières (Canada): Université du Québec à Trois-Rivières, 1996. 
Acessível em: <http:/ books. google. com. br/ books/ about/ L_origine_de_la doctrine_de_la_vertu_com.html? id= Lw7gtgAACAAJ\&redir_esc $=y>$.

HAMELIN, O. "Le système d'Aristote". $3^{\mathrm{a}}$ ed. Paris: Librairie philosophique J. Vrin, 1976.

KIDD. "Stoic Intermediates and the End for Man". In: Problems in Stoicism. Ed. A.A. Long. London: The Athlone Press, 1971.

LONG, A. A., SEDLEY, D.N. "The Hellenistic Philosophers. II. Greek and Latin Texts, with Notes and Bibliography". Cambridge: Cambridge University Press, 1987. LUSCOMBE, D. "Peter Abelard". In: P. Dronke (ed.). A History of Twelfth-Century Western Philosophy. Cambridge: Cambridge University Press, 1988. 